\title{
Aggregation of two imperfectly detected imperilled freshwater fishes: understanding community structure and co-occurrence for multispecies conservation
}

\author{
Karl A. Lamothe ${ }^{1, *}$, Alan J. Dextrase ${ }^{2}$, D. Andrew R. Drake ${ }^{1}$ \\ ${ }^{1}$ Great Lakes Laboratory for Fisheries and Aquatic Sciences, Fisheries and Oceans Canada, Burlington, ON L7S 1A1, Canada \\ ${ }^{2}$ Natural Resources Conservation Policy Branch, Ontario Ministry of Natural Resources and Forestry, Peterborough, \\ ON K9J 3C7, Canada
}

\begin{abstract}
Characterizing critical habitat for endangered species is the first step for effective conservation and relies on knowledge of the abiotic conditions that promote species occurrence. Knowledge of biotic interactions, a component of species habitat, can also provide vital information for the conservation of endangered species by identifying conditions and/or locations suitable for multispecies conservation. We investigated site-level species co-occurrence patterns for 2 federally protected fish species in Canada, eastern sand darter Ammocrypta pellucida and silver shiner Notropis photogenis, to determine if management measures applied to one species could confer benefits to the other species. Using repeat surveys of fish communities in the Grand River, Ontario, we developed 2-species occupancy models to control for imperfect detection while evaluating species co-occurrence patterns and related those patterns to abiotic habitat covariates. We also used a principal component analysis (PCA) to characterize observed fish community structure and fit abiotic variables to PCA axes to explain observed patterns. Results indicated aggregation between the 2 federally protected species in the Grand River; the probability of occupancy for $N$. photogenis was higher at sites where A. pellucida was present. Results from the PCA and cooccurrence models confirmed the importance of depth, water clarity, and water velocity for both species. The result of site-level aggregation after correcting for imperfect detection suggests that management measures applied to one species could confer benefits to the other; however, the mechanisms underlying co-occurrence remain poorly understood.
\end{abstract}

KEY WORDS: Biotic interactions • Endangered species · Freshwater fish • Habitat . Occupancy modelling

\section{INTRODUCTION}

Characterizing species-habitat associations is fundamentally important when developing recovery strategies for endangered fishes because knowledge of abiotic conditions that support fish populations allows managers to identify and protect areas of critical habitat (Rice 2005, Barletta et al. 2010). In Canada, critical habitat is defined under the Species at

${ }^{*}$ Corresponding author: karl.lamothe@dfo-mpo.gc.ca

$\S_{\text {Corrections }}$ were made after publication. For details see www.int-res.com/abstracts/esr/v40/c_p123-132/

This corrected version: February 4, 2020
Risk Act (SARA; Government of Canada 2002) as 'habitat that is necessary for the survival or recovery of a listed wildlife species and that is identified as the species' critical habitat in the recovery strategy or in an action plan for the species', where habitat for aquatic species is defined as 'spawning grounds and nursery, rearing, food supply, migration and any other areas on which aquatic species depend directly or indirectly in order to carry out their life processes,

(C) Ontario Ministry of Natural Resources and Forestry and Fisheries and Oceans Canada 2019. Open Access under Creative Commons by Attribution Licence. Use, distribution and reproduction are unrestricted. Authors and original publication must be credited. 
or areas where aquatic species formerly occurred and have the potential to be reintroduced' (Government of Canada 2002, p. 4). Therefore, fish habitat consists of all resources and conditions - abiotic and biotic - that support a given organism (Hall et al. 1997). While abiotic associations have been the subject of most habitat-related research for endangered fishes and represent an important science need to inform recovery strategies, understanding biotic interactions can also provide vital information for conservation managers (Angermeier \& Winston 1999, Wenger et al. 2011, Lamothe \& Drake 2019).

Biotic interactions are characterized by a direct relationship between 2 organisms at a given space and time. The relationship can occur between 2 individuals of the same species or between different species, and can be mutualistic $(+,+)$, predatory $(-,+)$, competitive $(-,-)$, commensalistic $(+, 0)$, or amensalistic $(-, 0)$. Despite the importance of identifying biotic interactions for aquatic restoration and species conservation (Halpern et al. 2007, Preston et al. 2008), biotic interactions have been relatively understudied compared to abiotic associations because they are often more difficult to measure in the wild, especially for endangered fishes. For example, it is difficult to observe nest associations or feeding behavior of small-bodied fishes that are found in turbid environments with non-lethal methods. These challenges preclude direct measurement of the mechanisms underlying biotic interactions for many aquatic organisms. Consequently, researchers often use species co-occurrence patterns as a proxy for biotic interactions by identifying whether species co-occur more than, less than, or as frequently as expected based on a hypothesis of independence (Peres-Neto 2004, Araújo et al. 2011). Although it is difficult to derive mechanisms of interactions from species co-occurrence patterns, analysis of co-occurrence provides insight into the direction of relationships between species, thereby informing future experimental work or providing evidence of shared or disparate abiotic preferences.

In addition to providing a better understanding of the local ecology of endangered fishes, testing for site-level patterns of positive or negative species cooccurrence, hereafter referred to as aggregation and segregation, respectively, has implications for the management of both species. For example, evidence of aggregation between 2 species would indicate that factors influencing the habitat patches of one species - whether restorative (i.e. habitat restoration) or destructive (i.e. habitat threats or other stressors) would preferentially influence the other species
(Halpern et al. 2007). Alternatively, evidence of segregation or independence would indicate that the 2 species require different habitat characteristics or that a negative interaction exists whereby the mechanism is unknown. For example, evidence of segregation could suggest a predator-prey relationship between 2 species. Nevertheless, understanding patterns of aggregation, segregation, and/or independence among co-occurring species, particularly endangered species, has direct implications for multispecies conservation planning (Halpern et al. 2007, Preston et al. 2008, DeCesare et al. 2010).

Southwestern Ontario has the highest diversity of freshwater fishes in Canada (Chu et al. 2008), but also contains the greatest number of SARA-listed freshwater fish species $(\mathrm{n}=20$ species; Staton \& Mandrak 2006, Hutchings \& Festa-Bianchet 2009). Most of these SARA-listed fishes are small bodied $(<20 \mathrm{~cm}$ total length), are at the northern limit of the species' range (Glass et al. 2017), and co-occur or cooccurred with other imperilled species in the region. For example, eastern sand darter Ammocrypta pellucida is a benthic percid listed under SARA as Threatened with populations distributed discontinuously at their northernmost extent within Ontario and Québec (COSEWIC 2009, Fisheries and Oceans Canada [DFO] 2011, 2012). A major threat to A. pellucida in Ontario is increased sedimentation leading to the loss of habitats containing sand and fine gravel substrates (DFO 2012), the favored habitat of A. pellucida (Daniels 1993, Drake et al. 2008, Dextrase et al. 2014). One of the few drainages supporting A. pellucida populations in Canada is the Grand River, Ontario, which also supports a population of silver shiner Notropis photogenis, a species listed as Threatened under SARA (DFO 2013, 20191). N. photogenis is a surface and midwater column feeding species known to be associated with moderately deep riverine habitats containing relatively high water clarity and moderate to fast water velocity (McKee \& Parker 1982, Glass et al. 2016). Although both species are extant in the Grand River drainage, it is unknown if A. pellucida and N. photogenis cooccur within small habitat patches (i.e. sites) more frequently than expected based on chance, and/or if these SARA-listed species display directional associations. For example, the burrowing and bottomdwelling behavior of $A$. pellucida could create a bottom disturbance, suspending particles and insects into the water column (e.g. Teresa \& Carvalho 2008),

\footnotetext{
${ }^{1}$ www.dfo-mpo.gc.ca/species-especes/profiles-profils/silvershiner-mene-miroir-eng.html
} 
benefiting the midwater column feeding N. photogenis. Alternatively, A. pellucida may compete for food resources with $N$. photogenis, particularly the juvenile stage, which does not display the same affinity for surface feeding.

The goals of this study were to evaluate co-occurrence patterns of 2 SARA-listed freshwater fish species in Canada (A. pellucida and N. photogenis) and relate patterns of co-occurrence to environmental covariates to assess the potential for multispecies conservation planning, including habitat restoration and the susceptibility to threats. We addressed 2 primary objectives related to abiotic associations and potential biotic interactions for A. pellucida and $N$. photogenis while accounting for imperfect detec-

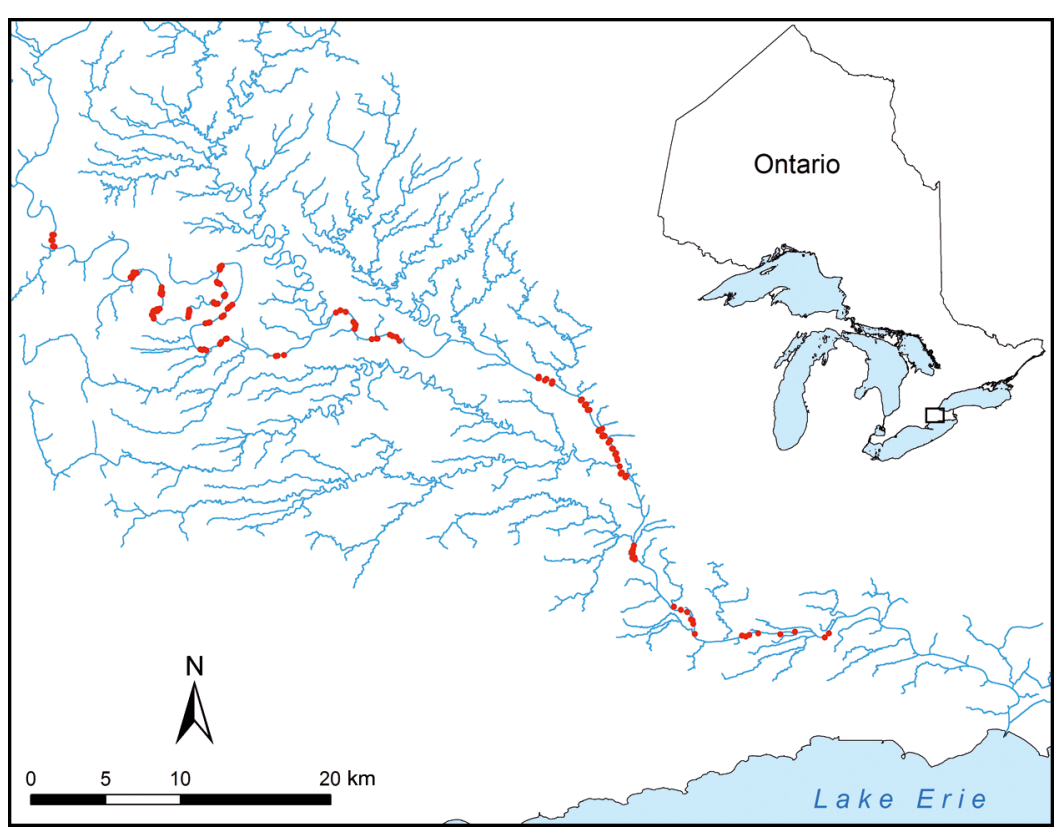

Fig. 1. Sampling sites ( $=151$ sites) on the Grand River, Ontario, Canada tion to determine (1) the direction and magnitude of the association between A. pellucida and $N$. photogenis occupancy in the Grand River watershed and (2) the relative importance of sand and fine gravel substrates, depth, and water clarity for A. pellucida and N. photogenis occupancy. Overall, our study provides novel insights into the joint abiotic and biotic associations for 2 federally listed fishes in Canada.

\section{MATERIALS AND METHODS}

\subsection{Data collection}

Fish and habitat surveys were performed at 151 sites along the main stem of the Grand River, Ontario, Canada (Fig. 1) in the summer of 2006 and 2007. The sampling scheme was originally designed to better understand habitat associations for Ammocrypta pellucida while considering the effects of imperfect detection (Dextrase 2013, Dextrase et al. 2014). Sampling sites were selected by stratifying the Grand River into 11 valley segments identified by Ontario Ministry of Natural Resources and Forestry Aquatic Landscape Inventory software (Stanfield \& Kuyvenhoven 2002), with the number of reaches per valley segment allocated in pro-

portion to the length of each segment; a minimum of 3 sites $\left(92 \mathrm{~m}^{2}\right.$ each) were sampled at each of the 31 identified reaches (Dextrase et al. 2014). Point measurements of depth $(\mathrm{cm})$, substrate size $(\mathrm{mm})$, and water clarity $(\mathrm{cm})$ were taken at each site, along with water velocity at $60 \%$ depth $\left(\mathrm{m} \mathrm{s}^{-1}\right.$; Table 1$)$. Substrate composition was assessed using a modified pebble count (Wolman 1954) and included the mean substrate size at the site as well as the proportion of pebble counts in the substrate categories: clay/silt $(<0.063 \mathrm{~mm})$, sand $(0.063-2.0 \mathrm{~mm})$, fine and medium sand (0.063-0.05 mm), fine gravel $(2.1-8.0 \mathrm{~mm})$, sand and fine gravel combined (0.063-8.0 mm), and coarse material (>8.0 mm; Dextrase 2013).

Sampling of fishes was performed by conducting 3 consecutive $10 \mathrm{~m}$ downstream hauls at each site with a $9.2 \mathrm{~m}$ bag seine (hence $92 \mathrm{~m}^{2}$ sites). After each haul,

Table 1. Environmental variables used in multivariate analysis and 2-species occupancy models

\begin{tabular}{|c|c|c|}
\hline Variable & Unit/category & Description \\
\hline Sand and fine gravel & Proportion & $\begin{array}{l}\text { Proportion of point pebble count } \\
\text { measures }(0.063-8.0 \mathrm{~mm})\end{array}$ \\
\hline Mean depth & $\mathrm{cm}$ & Mean depth at each site \\
\hline Mean substrate size & $\mathrm{mm}$ & $\begin{array}{l}\text { Mean of point pebble count measures } \\
\text { at each site }\end{array}$ \\
\hline Water clarity & $\mathrm{cm}$ & $\begin{array}{l}\text { Transparency based on a mid-depth } \\
\text { sample at center of site }\end{array}$ \\
\hline Water velocity & $\mathrm{m} \mathrm{s}^{-1}$ & $\begin{array}{l}\text { Mean water velocity at } 60 \% \text { depth } \\
\text { at each site }\end{array}$ \\
\hline
\end{tabular}


captured fishes were placed into separate holding aquaria, identified, and counted before release. For the purposes of occupancy modelling, we converted count data into detection and non-detection data (Fig. S1 in the Supplement at www.int-res.com/articles/suppl/ n040p123_supp.pdf provides a plot of A. pellucida and Notropis photogenis naïve relative abundance at sites where either species was captured; $\mathrm{n}=49$ sites). The 3 repeat seine hauls were used as repeated surveys at each site for modelling occupancy and detection, whereas the 3 hauls were combined into a single observation of abundance for multivariate analyses.

\subsection{Multivariate analysis}

We performed a principal component analysis (PCA) on the observed fish community abundance data and fit environmental vectors onto the PCA ordination plot to visualize community and speciesspecific habitat associations. The fish community data were Hellinger transformed prior to performing the PCA, and nontrivial axes were retained through permutations (Legendre \& Gallagher 2001, Lamothe et al. 2018). We permuted each column of the transformed community data matrix and conducted a PCA 9999 times; a component was retained if the proportion of variance explained in the observed data was greater than $95 \%$ of the permuted PCAs for that component (Peres-Neto et al. 2003, 2005). Pearson correlations were calculated to ensure a lack of correlation between abiotic variables. Mean substrate size, depth, and water clarity measures were scaled and centered (i.e. $z$-scores) prior to fitting them to the significant PCA axes. Squared correlation coefficients $\left(\mathrm{r}^{2}\right)$ were calculated for each environmental variable and the significant PCA axes, and their significance was assessed using 9999 permutations.

\subsection{Occupancy models}

We developed maximum-likelihood based, singleseason 2-species occupancy models for A. pellucida and $N$. photogenis with notation described by Richmond et al. (2010). With a 2-species occupancy modelling approach, sampling sites could be characterized as one of 4 mutually exclusive states: (1) A. pellucida and $N$. photogenis are both present, (2) A. pellucida is present and $N$. photogenis is absent, (3) A. pellucida is absent and $N$. photogenis is present, and (4) A. pellucida and $N$. photogenis are both absent.

We compared 9 possible detection models that in- cluded 1 or 2 detection covariates and used the best detection model to examine patterns of occupancy. Variables considered in the detection models included a species-specific detection parameter, a variable characterizing species removal after each seine haul, and scaled and centered site-specific mean substrate size (Table 1). The removal variable consisted of a row vector of survey-specific species removal history, whereby a 0 was assigned for a haul when the species was not detected in a previous haul, and a 1 was assigned when the species was captured in a previous seine haul (Table 1; Dextrase et al. 2014). For example, if $A$. pellucida had a detection history of $\mathrm{X}_{\mathrm{i}}^{\mathrm{A}}=101$ (i.e. detected, not detected, and detected), removal of $A$. pellucida at site $i$ would be coded as 011 (i.e. not removed, removed, removed).

We developed 17 occupancy models to consider combinations of site-specific habitat covariates (scaled and centered water clarity, depth, water velocity, and the proportion of sand and fine gravel), speciesspecific effects, and interactions between species whereby the presence of $A$. pellucida has an effect on the presence of $N$. photogenis. Three models failed to converge and were removed from the analysis. We compared candidate models using Akaike's information criterion (AIC), where the best models had the lowest AIC scores and a $\triangle \mathrm{AIC}$ of less than 2 units.

A species interaction factor $(\varphi)$ can be derived from occupancy probabilities to identify positive, negative, or independent associations between species using:

$$
\varphi=\frac{\psi^{\mathrm{A}} \psi^{\mathrm{BA}}}{\psi^{\mathrm{A}}\left[\psi^{\mathrm{A}} \psi^{\mathrm{BA}}+\left(1-\psi^{\mathrm{A}}\right) \psi^{\mathrm{Ba}}\right]}
$$

where $\psi^{\mathrm{A}}=$ probability of occupancy for A. pellucida, $\psi^{\mathrm{BA}}=$ probability of occupancy for $N$. photogenis with A. pellucida present, and $\psi^{\mathrm{Ba}}=$ probability of occupancy for $N$. photogenis with $A$. pellucida absent. When species occur independently, $\varphi=1$. When $\varphi<$ $1, N$. photogenis is less likely to co-occur with A. pellucida than expected under a hypothesis of independence (i.e. segregation). In contrast, when $\varphi>1$, $N$. photogenis is more likely to co-occur with $A$. pellucida than expected under a hypothesis of independence (i.e. aggregation; Richmond et al. 2010). Note that significant aggregation or segregation patterns do not imply direct species interactions but instead suggest that when imperfect detection is accounted for, A. pellucida and N. photogenis cooccur more or less frequently than expected under a hypothesis of independence.

All analyses were performed in R (Version 3.5.1; R Core Team 2018) using the psych (Revelle 2018), 
RPresence (MacKenzie \& Hines 2018), and vegan (Oksanen et al. 2018) packages and plotted using the base R functions and ggplot2 package (Wickham 2016). Data and R code can be found at https:// github.com/KarlLamothe/ESD_SS_GrandRiver.

\section{RESULTS}

\subsection{Fish community description}

In total, 49 species representing 34 genera were observed in the Grand River (Table S1 in the Supplement). Spotfin shiner Cyprinella spiloptera was the most prevalent species across sites (90.1\% of sites), whereas many species were only observed at a single site (brindled madtom Noturus miurus, brook stickleback Culaea inconstans, creek chub Semotilus atromaculatus, mooneye Hiodon tergisus, northern pike Esox lucius, northern sunfish Lepomis peltastes, river chub Nocomis micropogon, and white perch Morone americana). Eastern sand darter Ammocrypta pellucida was observed at 34 sites $(22.5 \%$ of sampled sites), silver shiner Notropis photogenis was observed at 29 sites (19.2\% of sampled sites), and the 2 species were observed co-occurring at 12 sites $(7.9 \%$ of sampled sites).

Four axes were extracted from the community PCA explaining $25.68 \%$ of the total variation in observed community composition (Fig. 2). Based on random permutations, water clarity, water velocity, and site depth were significant $(\mathrm{p}<0.05)$ predictors of community composition (Fig. 2), with $\mathrm{r}^{2}$ values ranging from 0.17 (depth) to 0.47 (water velocity). Notably, the proximity of $A$. pellucida and $N$. photogenis in ordination space indicates that patterns of relative abundance in the Grand River are similar and that both species relate to areas with higher water clarity, depth, and water velocity (Fig. 2).

\subsection{Occupancy models}

The model-averaged probability of detection across sites was $0.605 \pm 0.029 \mathrm{SE}$ for A. pellucida and $0.480 \pm 0.030 \mathrm{SE}$ for $N$. photogenis. The best detection model included mean substrate size, where the effect of mean substrate size differed between species (Table 2, Fig. 3). As substrate size increased, detection probability for both species decreased (Fig. 3). The model-averaged probability of occupancy in the Grand River was $0.327 \pm 0.021$ SE for $A$. pellucida and $0.455 \pm 0.008 \mathrm{SE}$ for $N$. photogenis. In
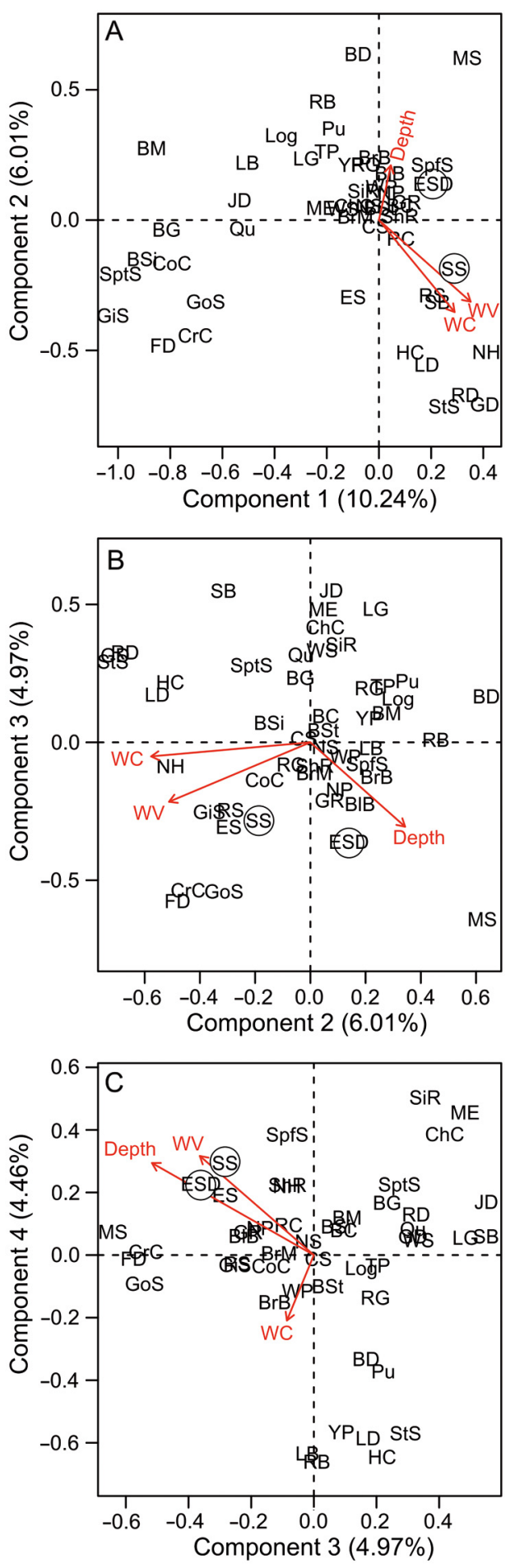

Fig. 2. Biplots of the (A) first and second, (B) second and third, and (C) third and fourth significant community ordination axes and environmental vectors. Species are shown in black, and significant $(\mathrm{p}<0.05)$ environmental vectors are shown in red. Species codes can be found in Table S1 in the Supplement at www.int-res.com/articles/suppl/n040p123_ supp.pdf. WC: water clarity $(\mathrm{cm})$; WV: water velocity $\left(\mathrm{m} \mathrm{s}^{-1}\right)$. Circled are eastern sand darter Ammocrypta pellucida (ESD) and silver shiner Notropis photogenis (SS) 
Table 2. Summary of occupancy models selected using Akaike's information criterion (AIC). LL: log likelihood; npar: number of parameters in the model; $\psi$ : occupancy probability; $R$ : removal; SP: species-level effect; Substrate: mean substrate size (mm); (.) intercept model; INT: occurrence-level interaction between species; sfg: proportion of sand and fine gravel; p: detection probability; WV: water velocity $\left(\mathrm{m} \mathrm{s}^{-1}\right)$; WC: water clarity $(\mathrm{cm})$; Depth: mean depth $(\mathrm{m})$

\begin{tabular}{|c|c|c|c|c|c|c|}
\hline Model & AIC & $\Delta \mathrm{AIC}$ & $\begin{array}{l}\text { Akaike } \\
\text { weight }\end{array}$ & $-2 \mathrm{LL}$ & npar & $\varphi$ \\
\hline$\psi(\mathrm{INT}+\mathrm{SP} \cdot \mathrm{sfg}), p(\mathrm{SP} \cdot \mathrm{Substrate})$ & 472.65 & 0.00 & 0.708 & 454.65 & 9 & 2.055 \\
\hline$\psi(\mathrm{SP} \cdot \mathrm{WV}), p(\mathrm{SP} \cdot \mathrm{Substrate})$ & 476.19 & 3.54 & 0.120 & 460.19 & 8 & 1.000 \\
\hline$\psi(\mathrm{SP}+\mathrm{WV}), p(\mathrm{SP} \cdot$ Substrate $)$ & 476.83 & 4.18 & 0.088 & 462.83 & 7 & 1.000 \\
\hline$\psi(\mathrm{SP} \cdot \mathrm{sfg}), p(\mathrm{SP} \cdot \mathrm{Substrate})$ & 478.11 & 5.46 & 0.046 & 462.11 & 8 & 1.000 \\
\hline$\psi(\mathrm{SP}+\mathrm{sfg}), p(\mathrm{SP} \cdot \mathrm{Substrate})$ & 478.53 & 5.88 & 0.037 & 464.53 & 7 & 1.000 \\
\hline$\psi(\mathrm{INT}+\mathrm{SP}+\mathrm{WC}), p(\mathrm{SP} \cdot$ Substrate $)$ & 496.31 & 23.66 & $<0.001$ & 480.31 & 8 & 1.723 \\
\hline$\psi(\mathrm{INT}+\mathrm{SP} \cdot \mathrm{WC}), p(\mathrm{SP} \cdot$ Substrate $)$ & 497.98 & 25.33 & $<0.001$ & 479.98 & 9 & 1.814 \\
\hline$\psi(\mathrm{SP}+\mathrm{WC}), p(\mathrm{SP} \cdot$ Substrate $)$ & 501.73 & 29.08 & $<0.001$ & 487.73 & 7 & 1.000 \\
\hline$\psi(\mathrm{SP} \cdot \mathrm{WC}), p(\mathrm{SP} \cdot \mathrm{Substrate})$ & 503.26 & 30.61 & $<0.001$ & 487.26 & 8 & 1.000 \\
\hline$\psi($ Depth + INT + SP $), p(\mathrm{SP} \cdot$ Substrate $)$ & 506.15 & 33.50 & $<0.001$ & 490.15 & 8 & 1.783 \\
\hline$\psi($ INT + Depth $\cdot$ SP $), p($ SP $\cdot$ Substrate $)$ & 508.08 & 35.42 & $<0.001$ & 490.08 & 9 & 1.796 \\
\hline$\psi($ Depth + SP),$p($ SP $\cdot$ Substrate $)$ & 510.33 & 37.68 & $<0.001$ & 496.33 & 7 & 1.000 \\
\hline$\psi($ Depth $\cdot$ SP $), p($ SP $\cdot$ Substrate $)$ & 512.33 & 39.68 & $<0.001$ & 496.33 & 8 & 1.000 \\
\hline$\psi(),. p(\mathrm{SP} \cdot$ Substrate) & 520.99 & 48.34 & $<0.001$ & 510.99 & 5 & 1.000 \\
\hline$\psi(\mathrm{SP}), p(\mathrm{SP} \cdot \mathrm{Substrate})$ & 522.94 & 50.28 & $<0.001$ & 510.94 & 6 & 1.000 \\
\hline$\psi(),. p(\mathrm{SP}+$ Substrate $)$ & 530.04 & 57.39 & $<0.001$ & 522.04 & 4 & 1.000 \\
\hline$\psi(),. p(R+\mathrm{SP})$ & 531.91 & 59.26 & $<0.001$ & 523.91 & 4 & 1.000 \\
\hline$\psi(),. p(R+$ Substrate $)$ & 532.46 & 59.81 & $<0.001$ & 524.46 & 4 & 1.000 \\
\hline$\psi(),. p(R \cdot \mathrm{SP})$ & 533.08 & 60.42 & $<0.001$ & 523.08 & 5 & 1.000 \\
\hline$\psi(),$.$p (Substrate)$ & 537.69 & 65.04 & $<0.001$ & 531.69 & 3 & 1.000 \\
\hline$\psi(),. p(\mathrm{SP})$ & 538.74 & 66.09 & $<0.001$ & 532.74 & 3 & 1.000 \\
\hline$\psi(),. p(R)$ & 554.63 & 81.98 & $<0.001$ & 548.63 & 3 & 1.000 \\
\hline$\psi(),. p()$. & 558.37 & 85.72 & $<0.001$ & 554.37 & 2 & 1.000 \\
\hline
\end{tabular}

the absence of A. pellucida, modelaveraged $N$. photogenis occupancy was $0.330 \pm 0.008 \mathrm{SE}$, whereas in the presence of A. pellucida, model-averaged $N$. photogenis occupancy was $0.715 \pm 0.010$ SE.

The best occupancy model included the proportion of sand and fine gravel, where the effect of the proportion of sand and fine gravel on occupancy differed between species, as well as an interaction term (INT; Table 2). The interaction term indicates that the presence of $A$. pellu-

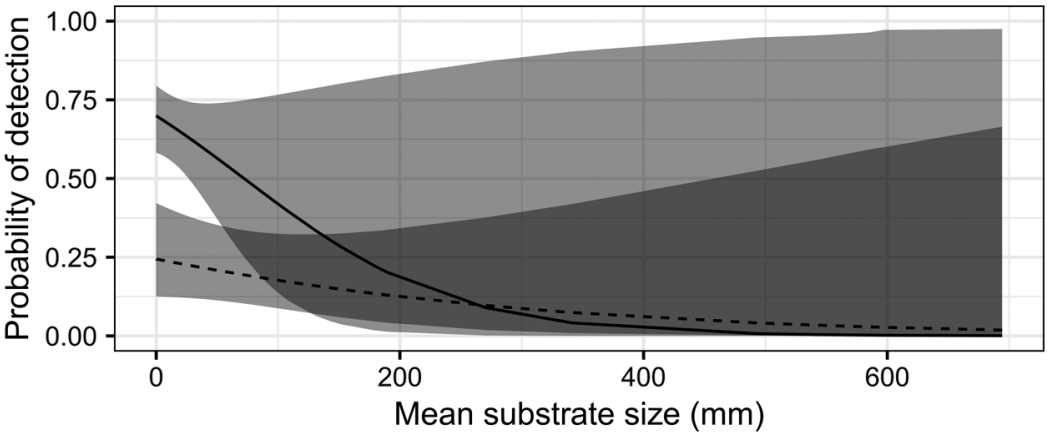

Fig. 3. Probability of detection across mean substrate size (mm) for eastern sand darter Ammocrypta pellucida (solid line) and silver shiner Notropis photogenis (dashed line). Ribbons indicate upper and lower $95 \%$ CIs cida had an effect on the probability of occupancy for $N$. photogenis, but the effect was constant with respect to the proportion of sand and fine gravel at a site. The species interaction factor $(\varphi)$ for the top occupancy model indicated a positive association between A. pellucida and $N$. photogenis across sites $\left(\varphi=2.055 \pm 0.104 \mathrm{SE}_{;}\right.$Table 2$)$; similarly, the remaining models with interaction terms all estimated a positive association $(\varphi>1$; Table 2$)$.

We used the best models that included either the proportion of sand and fine gravel, depth, water clarity, or water velocity to investigate patterns of occupancy across habitat covariates (Fig. 4). The proba- bility of occupancy for A. pellucida increased with higher proportions of sand and fine gravel, depth, water clarity, and water velocity (Fig. 4). Similarly, the probability of occupancy for $N$. photogenis increased with depth, water clarity, and water velocity but showed a unimodal response to the proportion of sand and fine gravel (Fig. 4). Across all proportions of sand and fine gravel, depths, and water clarity values, the probability of $N$. photogenis occupancy was always higher when $A$. pellucida was present than when A. pellucida was absent (Fig. 4)-consistent with expectations from $\varphi$ calculations (Table 2) and the results of multivariate analysis (Fig. 2). 


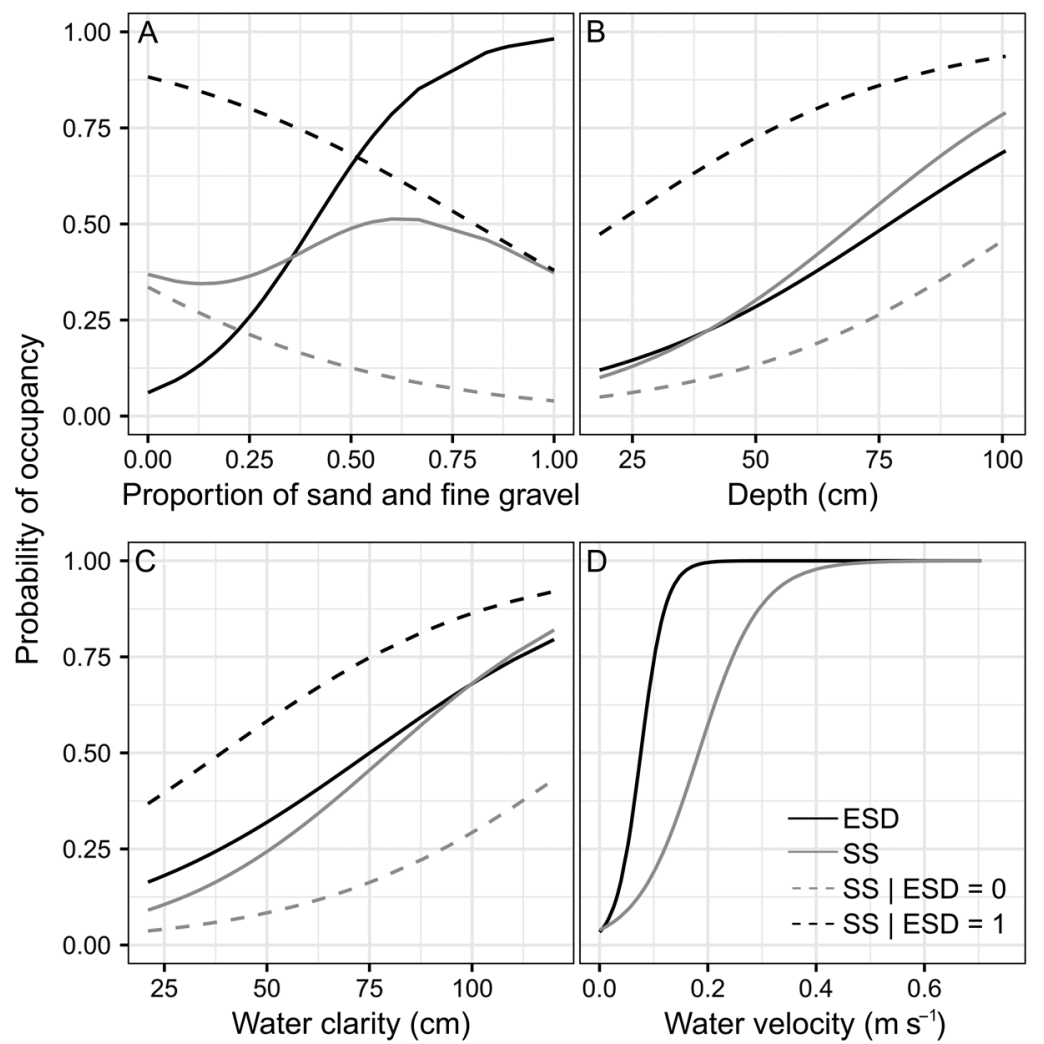

Fig. 4. Probability of occupancy as a function of (A) the proportion of sand and fine gravel, (B) depth, (C) water clarity, and (D) water velocity for eastern sand darter Ammocrypta pellucida (ESD), silver shiner Notropis photogenis (SS), N. photogenis with A. pellucida absent (SS I ESD =0), and N. photogenis with $A$. pellucida present (SS I ESD $=1$ ). Note that models including both water velocity and species interactions failed to converge

\section{DISCUSSION}

Aggregation patterns between 2 federally listed species, whereby the 2 species show similar patterns of occupancy across abiotic covariates, have important conservation implications given the challenges associated with species protection. Based on the positive association between Ammocrypta pellucida and Notropis photogenis in the Grand River and the species' similar responses to abiotic features (i.e. water clarity, depth, and water velocity), management to improve water clarity would likely return twice the expected benefits from a single restoration measure. A long-standing debate exists about whether imperilled species should be protected through speciesspecific management or management at the ecosystem or landscape scale (e.g. Simberloff 1998, Franklin 1993, Poos et al. 2008). An intermediate approach that blends species- and ecosystem-based approaches is the protection of an umbrella species, or a species for which species-specific protection would confer protection to a large number of co-occurring species (Launer \& Murphy 1994). Based on the ordination of naïve community observations, which showed consistent patterns with our occupancy models, $N$. photogenis shared habitat associations with $A$. pellucida and several minnow species, including mimic shiner $N$. volucellus, spotfin shiner Cyprinella spiloptera, and rosyface shiner N. rubellus. Perhaps N. photogenis represents an umbrella species, whereby management to improve $N$. photogenis habitat (i.e. water clarity and flow regime) would lead to benefits for several other species. Alternatively, the presence of these common species (i.e. C. spiloptera, $N$. rubellus, and $N$. volucellus) may provide an indication of potentially suitable habitat to support $N$. photogenis or habitat that could be selected for restoration.

Although species co-occurrence was used here as a proxy for biotic interactions, the mechanism behind the positive association is still unknown. It is possible that the scale of sampling was larger than actual microhabitats selected by A. pellucida and $N$. photogenis, and therefore the positive association was an artefact of sampling. Based on an allometric relationship (Minns 1995), the home range for an average-sized adult $A$. pellucida (Ontario average: $60 \mathrm{~mm}$; Holm et al. 2009) is approximately $47 \mathrm{~m}^{2}$, whereas the home range of an average-sized adult $N$. photogenis $(100 \mathrm{~mm}$; Holm et al. 2009) is approximately $109 \mathrm{~m}^{2}$. The sampling approach employed in this study focused on erosional and depositional bars of river reaches, the anticipated habitat for A. pellucida, and was performed using a bag seine over $92 \mathrm{~m}^{2}$ sites (Dextrase 2013). Seining is an approach that covers the entirety of the water column and therefore does not allow differentiation between how species are vertically distributed. However, A. pellucida is a benthic species that feeds on small bottom-dwelling invertebrates (Fisheries and Oceans Canada 2012), whereas N. photogenis is an opportunistic feeder that capitalizes on aquatic invertebrates throughout the water column, including jumping out of the water to capture airborne insects (COSEWIC 2011). As such, positive co- 
occurrence patterns could indicate correlated areas of foraging, whereby the smaller A. pellucida is residing in the benthic zone and the larger $N$. photogenis is residing in mid-column areas.

A finding of segregation between federally listed species, contrary to results presented here, would have more challenging conservation implications and would likely require protection of unique habitats. For example, we recently demonstrated negative co-occurrence patterns between $A$. pellucida and johnny darter Etheostoma nigrum and rainbow darter E. caeruleum in Ontario, 2 species widely present across the southern Ontario landscape (Lamothe et al. 2019). Based on our present multivariate analysis, E. nigrum and E. caeruleum were associated with areas of lower flows and shallower depths (Fig. 2). If the general protection of darters was a key management objective, then it is possible that the scale of management would change by focusing on multiple habitat types, with different flow characteristics, rather than focusing on water clarity alone.

Our study also demonstrates the importance of repeat sampling to account for imperfect detection when characterizing patterns of species distributions, co-occurrence, and community assembly. Imperfect detection commonly impacts monitoring efforts for imperilled species (MacKenzie et al. 2002), as their rarity often requires unique sampling approaches. In this study, N. photogenis was detected infrequently in the Grand River (19.2\% of sites) but had an average detection probability of approximately 0.5. As a result, the estimated mean occupancy probability was more than twice that from the naïve sampling data. Nevertheless, the results of our community analysis performed on the observed data showed similar habitat association results to those from our species co-occurrence models that incorporated the probability of detection. For example, N. photogenis was found near the tip of the water velocity vector within the community ordination (Fig. 2), indicating an association with habitats having higher water velocity, which is consistent with the literature (Glass et al. 2016) and the occupancy model results (Fig. 4D).

Understanding and quantifying patterns of species distributions, co-occurrence, and community assembly is fundamental for protecting endangered species. While traditional species distribution models based on abiotic relationships provide important insight into habitat components critical for sustaining populations (Anderson \& Martínez-Meyer 2004, Williams et al. 2009), knowledge of imperilled species co-occurrence and community assembly patterns can help identify sites or biotic assemblages where the species is, or is not, likely to occur (Bailey et al. 2009, Cove et al. 2018). This is particularly important in diverse systems such as the Grand River, one of the most speciose rivers in Canada, and also helps to manage against impending human-mediated changes (the Ontario population is projected to grow to $\sim 18$ million people by 2041; Ontario Ministry of Finance 2018). However, the Grand River is also subject to a suite of environmental stressors threatening species persistence (e.g. Balasingham et al. 2018, Dean et al. 2018, Raab et al. 2018, Hanief \& Laursen 2019). The results of our study indicate that improving water clarity in this watershed will benefit fish species that are most in need of protection, supporting recommendations in federal recovery documents (DFO 2012) and the longstanding goals of many aquatic restoration programs (e.g. Allison \& Meselhe 2010).

Acknowledgements. The authors thank G. Lunn and the many field technicians who assisted in collecting the species and habitat data. We also thank N. Wasilik for curating our sampling map and D. I. MacKenzie for R coding support. Funding for field sampling was provided by the Ontario Ministry of Natural Resources and Forestry, Fisheries and Oceans Canada's Species at Risk Program, Trent University, and the Endangered Species Recovery Fund of World Wildlife Fund Canada and Environment Canada. Funding for K.A.L. was provided by a Natural Sciences and Engineering Research Council of Canada Visiting Fellowship with Fisheries and Oceans Canada.

\section{LITERATURE CITED}

Allison MA, Meselhe EA (2010) The use of large water and sediment diversions in the lower Mississippi River (Louisiana) for coastal restoration. J Hydrol (Amst) 387: 346-360

Anderson RP, Martínez-Meyer E (2004) Modeling species' geographic distributions for preliminary conservation assessments: an implementation with the spiny pocket mice (Heteromys) of Ecuador. Biol Conserv 116:167-179

Angermeier PL, Winston MR (1999) Characterizing fish community diversity across Virginia landscapes: prerequisite for conservation. Ecol Appl 9:335-349

Araújo MB, Rozenfeld A, Rahbek C, Marquet PA (2011) Using species co-occurrence networks to assess the impacts of climate change. Ecography 34:897-908

Bailey LL, Reid JA, Forsman ED, Nichols JD (2009) Modeling co-occurrence of northern spotted and barred owls: accounting for detection probability differences. Biol Conserv 142:2983-2989

Balasingham KD, Walter RP, Mandrak NE, Heath DD (2018) Environmental DNA detection of rare and invasive species in two Great Lakes tributaries. Mol Ecol 27:112-127

Barletta M, Jaureguizar AJ, Baigun C, Fontoura NF and others (2010) Fish and aquatic habitat conservation in South America: a continental overview with emphasis on Neotropical systems. J Fish Biol 76:2118-2176

Chu C, Jones NE, Mandrak NE, Piggott AR, Minns CK 
(2008) The influence of air temperature, groundwater discharge, and climate change on the thermal diversity of stream fishes in southern Ontario watersheds. Can J Fish Aquat Sci 65:297-308

COSEWIC (Committee on the Status of Endangered Wildlife in Canada) (2009) COSEWIC assessment and status report on the eastern sand darter Ammocrypta pellucida, Ontario populations and Quebec populations, in Canada. Committee on the Status of Endangered Wildlife in Canada, Ottawa, ON

COSEWIC (2011) COSEWIC assessment and status report on the silver shiner Notropis photogenis in Canada. Committee on the Status of Endangered Wildlife in Canada, Ottawa, ON

Cove MV, Gardner B, Simons TR, O'Connell AF (2018) Cooccurrence dynamics of endangered Lower Keys marsh rabbits and free-ranging domestic cats: prey responses to an exotic predator removal program. Ecol Evol 8: 4042-4052

Daniels RA (1993) Habitat of the eastern sand darter, Ammocrypta pellucida. J Freshw Ecol 8:287-295

Dean BY, Corcoran PL, Helm PA (2018) Factors influencing microplastic abundances in nearshore, tributary and beach sediments along the Ontario shoreline of Lake Erie. J Gt Lakes Res 44:1002-1009

DeCesare NJ, Hebblewhite M, Robinson HS, Musiani M (2010) Endangered, apparently: the role of apparent competition in endangered species conservation. Anim Conserv 13:353-362

Dextrase AJ (2013) Modelling occupancy and abundance of eastern sand darter (Ammocrypta pellucida) while accounting for imperfect detection. PhD dissertation, Trent University, Peterborough, ON

Dextrase AJ, Mandrak NE, Schaeffer JA (2014) Modelling occupancy of an imperilled stream fish at multiple scales while accounting for imperfect detection: implications for conservation. Freshw Biol 59:1799-1815

DFO (2011) Recovery potential assessment of eastern sand darter (Ammocrypta pellucida) in Canada. DFO Can Sci Advis Sec Sci Advis Rep 2011/020

DFO (2012) Recovery strategy for the eastern sand darter (Ammocrypta pellucida) in Canada: Ontario populations. Species at Risk Act Recovery Strategy Series. Fisheries and Oceans Canada, Ottawa, ON

DFO (2013) Recovery potential assessment of silver shiner (Notropis photogenis) in Canada. DFO Can Sci Advis Sec Sci Advis Rep 2012/068

* Drake DAR, Power M, Koops MA, Doka SE, Mandrak NE (2008) Environmental factors affecting growth of eastern sand darter (Ammocrypta pellucida). Can J Zool 86: 714-722

Franklin JF (1993) Preserving biodiversity: species, ecosystems, or landscapes? Ecol Appl 3:202-205

Glass WR, Gaspardy R, Barnucz J, Bouvier LD, Mandrak NE (2016) Silver shiner (Notropis photogenis) in Ontario: distribution and habitat use. Can Manuscr Rep Fish Aquat Sci 3105

Glass WR, Corkum LD, Mandrak NE (2017) Living on the edge: traits of freshwater fish species at risk in Canada. Aquat Conserv: Mar Freshw Ecosyst 27:938-945

Government of Canada (2002) Species at Risk Act (SARA), SC 2002, c 29. https://laws-lois.justice.gc.ca/eng/acts/s-15.3/

Hall LS, Krausman PR, Morrison ML (1997) The habitat concept and a plea for standard terminology. Wildl Soc Bull 25:173-182
Halpern BS, Silliman BR, Olden JD, Bruno JP, Bertness MD (2007) Incorporating positive interactions in aquatic restoration and conservation. Front Ecol Environ 5:153-160

*Hanief A, Laursen AE (2019) Meeting updated phosphorus reduction goals by applying best management practices in the Grand River watershed, southern Ontario. Ecol Eng 130:169-175

Holm E, Mandrak NE, Burridge ME (2009) The ROM field guide to freshwater fishes of Ontario. Friesens Printers, Altona, Manitoba

Hutchings JA, Festa-Bianchet M (2009) Canadian species at risk (2006-2008), with particular emphasis on fishes. Environ Rev 17:53-65

Lamothe KA, Drake DAR (2019) Moving repatriation efforts forward for imperilled Canadian freshwater fishes. Can J Fish Aquat Sci 76:1914-1921

* Lamothe KA, Jackson DA, Somers KM (2018) Long-term directional trajectories among lake crustacean zooplankton communities and water chemistry. Can J Fish Aquat Sci 75:1926-1939

Lamothe KA, Dextrase AJ, Drake DAR (2019) Characterizing species co-occurrence patterns of imperfectly detected stream fishes to inform species reintroduction efforts. Conserv Biol (in press), doi:10.1111/cobi.13320

* Launer AE, Murphy DD (1994) Umbrella species and the conservation of habitat fragments: a case of a threatened butterfly and a vanishing grassland ecosystem. Biol Conserv 69:145-153

* Legendre P, Gallagher ED (2001) Ecologically meaningful transformations for ordination of species data. Oecologia 129:271-280

MacKenzie DI, Hines J (2018) RPresence: R interface for program PRESENCE. R package version 2.12.22

* MacKenzie DI, Nichols JD, Lachman GB, Droege S, Royle JA, Langtimm CA (2002) Estimating site occupancy rates when detection probabilities are less than one. Ecology 83:2248-2255

McKee PM, Parker BJ (1982) The distribution, biology, and status of the fishes Campostoma anomalum, Clinostomus elongatus, Notropis photogenis (Cyprinidae), and Fundulus notatus (Cyprinodontidae) in Canada. Can J Zool 60:1347-1358

Minns CK (1995) Allometry of home range size in lake and river fishes. Can J Fish Aquat Sci 52:1499-1508

Oksanen J, Blanchet FG, Friendly M, Kindt R and others (2018) vegan: community ecology package. R package version $2.5-2$

Ontario Ministry of Finance (2018) Ontario population projections update based on the 2011 census: 2017-2041 Ontario and its 49 census divisions. Queen's Printer for Ontario, Toronto, ON

Peres-Neto PR (2004) Patterns in the co-occurrence of fish species in streams: the role of site suitability, morphology and phylogeny versus species interactions. Oecologia 140:352-360

* Peres-Neto PR, Jackson DA, Somers KM (2003) Giving meaningful interpretation to ordination axes: assessing loading significance in principal component analysis. Ecology 84:2347-2363

* Peres-Neto PR, Jackson DA, Somers KM (2005) How many principal components? Stopping rules for determining the number of non-trivial axes revisited. Comput Stat Data Anal 49:974-997

* Poos MS, Mandrak NE, McLaughlin RL (2008) A practical framework for selecting among single-species, commu- 
nity-, and ecosystem-based recovery plans. Can J Fish Aquat Sci 65:2656-2666

Preston KL, Rotenberry JT, Redak RA, Allen MF (2008) Habitat shifts of endangered species under altered climate conditions: importance of biotic interactions. Glob Change Biol 14:2501-2515

R Core Team (2018) R: a language and environment for statistical computing. R Foundation for Statistical Computing, Vienna

Raab D, Mandrak NE, Ricciardi A (2018) Low-head dams facilitate round goby Neogobius melanostomus invasion. Biol Invasions 20:757-776

Revelle W (2018) psych: procedures for personality and psychological research, Northwestern University, Evanston, IL

Rice JC (2005) Understanding fish habitat ecology to achieve conservation. J Fish Biol 67:1-22

Richmond OMW, Hines JE, Beissinger SR (2010) Twospecies occupancy models: a new parameterization applied to co-occurrence of secretive rails. Ecol Appl 20: 2036-2046

Simberloff D (1998) Flagships, umbrellas, and keystones: Is species-species management passé in the landscape era? Biol Conserv 83:247-257

Stanfield LW, Kuyvenhoven R (2002) Protocol for applications used in the Aquatic Landscape Inventory soft-

Editorial responsibility: Eduardo Martins, Vancouver, British Columbia, Canada ware application for delineating, characterizing and classifying valley segments within the Great Lakes basin. Ontario Ministry of Natural Resources, Glenora, $\mathrm{ON}$

Staton SK, Mandrak NE (2006) Focusing conservation efforts for freshwater biodiversity. In: Nelson G, Nudds T, Beveridge M, Dempster B (eds) Protected areas and species and ecosystems at risk: research and planning challenges. Proceedings of the Parks Research Forum of Ontario Annual Meeting 2005. Parks Research Forum of Ontario, University of Waterloo, ON, p 197-204

* Teresa FB, Carvalho FR (2008) Feeding association between benthic and nektonic Neotropical stream fishes. Neotrop Ichthyol 6:109-111

*Wenger SJ, Isaak DJ, Luce $\mathrm{CH}$, Neville $\mathrm{HM}$ and others (2011) Flow regime, temperature, and biotic interactions drive differential decline of trout species under climate change. Proc Natl Acad Sci USA 108:14175-14180

Wickham H (2016) ggplot2: elegant graphics for data analysis. Springer-Verlag, New York, NY

Williams NJ, Seo C, Thorne J, Nelson JK, Erwin S, O'Brien JM, Schwartz MW (2009) Using species distribution models to predict new occurrences for rare plants. Divers Distrib 15:565-576

Wolman MG (1954) A method of sampling coarse river-bed material. Trans Am Geophys Union 35:951-956

Submitted: March 4, 2019; Accepted: August 1, 2019

Proofs received from author(s): October 16, 2019 